\title{
Application of dental stem cell in dentistry: where are we now?
}

\author{
Khairani Idah Mokhtar* \\ Department of Fundamental Dental and Medical Sciences, Kulliyyah of Dentistry, International Islamic \\ University Malaysia (IIUM), 25200, Kuantan, Pahang, Malaysia
}

*Corresponding author:
Address:
Department of Fundamental
Dental and Medical Sciences,
Kulliyyah of Dentistry,
International Islamic University
Malaysia (IIUM), 25200, Kuantan,
Pahang, Malaysia.
Telephone: +6095705500
Email address:
drkhairani@iium.edu.my

\section{Introduction}

Dental Stem Cells (DSC) appears to be closely linked to dentistry although the application of DSC has been widely acknowledged by other fields. DSC are undifferentiated cells obtained from the dental tissue. Specifically, these are undifferentiated cells with multipotential ability to differentiate into specific lineages. These stem cells are mesenchymal stem cell (MSC) which are harvested from specific dental tissues such as from the dental pulp of permanent teeth; DPSC (Dental Pulp Stem Cells), dental pulp of deciduous teeth; SHED (Stem Cell from Human Exfoliated Deciduous teeth) and from the periodontal ligament; PDLSC (Periodontal Ligament Stem Cells). Other dental stem cells could also be obtained from dental follicle of human third molar; DFSC (Dental Follicle Stem Cells) and from the apical papilla; SCAP (Stem Cells from Apical Papilla) (Abdullah et al., 2013; Botelho et al., 2017). Of these, DPSCs and SHEDs are dental stem cells which have been utilized in many of the tissue engineering and regeneration research.

Tissue engineering and regenerative medicine (TERM) is an evolving field in dentistry focusing on the development of alternative therapies for tissue and/or organ repair with the aim to induce the formation of new functional tissues. Tissue engineering requires input from the TRIAD key players; stem/progenitor cells, scaffolds for cell growth and important growth factors (Murphy et al., 2013). New development of nanomedicine, smart materials for cell and growth factor delivery as well as gene therapy provide better outcome hence overcome some of the limitations that currently exist in the clinics. Collaborative effort and interdisciplinary approaches are needed; involving clinicians as well as molecular biologists, stem cell researchers and material scientists, to ensure the output can be translated from bench to chairside or bedside.

DSC has been applied widely in many areas of research. The use of DPSC and SHED provide better choice due to its less invasiveness and reduce risk to the donors in comparison to other types of adult MSCs (Govindasamy et al., 2011). The use of other stem cell sources such as embryonic stem cells (ESC) raised ethical concerns while donor's for induced pluripotent stem cells (iPSC) are concern towards the invasive techniques performed during the collection of the tissues hence limiting the clinical use although ESC and iPSC are considered as the best sources of stem cells due to their 
pluripotency (Ghosh et al., 2016; Lee \& Seo, 2016; Huang et al., 2019).

In dentistry, DSC has been applied in dentalrelated clinical application research such as regenerative endodontics and periodontal regeneration research since its discovery way back in early 2000 (Gronthos et al., 2002; Miura et al., 2003). In pulp regeneration, stem cells from DPSC were isolated, cultured and harvested in vitro. Stem cells were seeded onto scaffolds incorporated with signaling molecules and transplanted into the root canal of ex vivo tooth slides or in situ canine tooth. The formation of pulp-like tissues (connective tissues with blood vessel formation and dentin-like tissue deposition) was observed in many experimental studies (Nakashima et al., 2017; 2011; Sun et al., 2014; Yang et al., $2015 \mathrm{a}, \mathrm{b})$ including one group utilizing SHED (https://clinicaltrials.gov/ct2/show/)

which hold promise in pulp revitalization and regeneration. The use of DSC also has been applied in many fundamental studies related to biomaterial and natural products. Overall, the ultimate aim of most of these studies are to determine if the DSCs can be differentiated into specific lineages and to function appropriately in the presence of suitable scaffold material and growth factors hence providing a suitable TRIAD to be subjected for future TERM applications.

So, DSC research in Malaysia, where are we now? To the best of our knowledge, research in DSC is mostly being carried out in institutions offering dental programme; involving both IPTAs and IPTS. Based on author's experience, research on DSC are performed by small groups of local researchers in these universities, starting from basic such as looking into cell morphology and gene expression (Abdullah et al., 2014) up into application such as looking into the potential of DSC to be differentiated into specific cell lineages (osteoblast-like cells, endothelial-like cells) when treated with certain growth factors or seeded on certain scaffolds (Farea et al., 2014; Hashim et al., 2019). According to a systematic review performed by Xuan et al., (2021), studies on regenerative potential of DSC from DPSC/SHED started to be published from 2009 onwards thus, suggesting that research in DSC already started few years earlier. Most of the research published include cell morphogenesis/proliferation and differentiation (dentinogenesis, cementoblast and osteogenesis), material biocompatibility and immunomodulation. DSC-based research also has been demonstrated to be further applied in research related to regenerative medicine looking into its potential in angiogenesis and cardiogenesis (Xuan et al., 2021). Although the publication from the local researchers is still very limited, it indicates the potential of DSC-related research to be one of the areas that will become important in the new future.

Researchers involved in DSC areas needs to have collaboration with other institutes; either locally or internationally. Collaboration with industries will also openup more potentials for DSC to be further applied in research and enhance publication. Collaboration with industries will also enable more high-end facilities to be utilized in stem cell research. Transfer of knowledge among the researchers are also important to ensure that we are being keeping abreast with all the new technologies which continue to expand limitlessly. Funding of grants from the responsible agencies is also require assisting the researchers to translate their research accordingly.

Overall, it is sufficient to say that DSC-related research is gaining its attention in Malaysia especially among the researchers. However, more are needed to be done especially on the public's awareness and knowledge regarding the importance of DSC since recent study-survey has demonstrated lack of awareness among Malaysians especially on the regenerative potential of DSC (Chiann et al., 2021). Spreading awareness and knowledge regarding DSC among other types of stem cells should be given to the secondary and tertiary students and must not only focused to those with healthsciences background. Needless to say, requirement and guidelines must also be outlined by the Malaysian authority to ensure the application of DSC follows 
appropriate standards in terms of safety, quality and efficacy before allowing the use of this stem cells in the near future.

\section{References}

Abdullah, M. F., Kannan, T. P. \& Mokhtar, K.I. (2013). DPSCs and SHED in tissue engineering and regenerative medicine. The Open Stem Cell Journal, 4, 1-6

Abdullah, M. F., Abdullah, S. F., Omar, N., Noor, S. N. F. M., Mahmood, Z., Mokhtar, K.I \& Kannan, T. P. (2014). Proliferation rate of stem cells derived from human dental pulp and identification of differentially expressed genes. Cell Biology International, 9999 1-9

Botelho, J., Cavacas, M. A., Machado, V., Mendes, J. J. 2017Dental stem cells: recent progresses in tissue engineering and regenerative medicine. ANNALS OF MEDICINE, 49(8):644-651. Epub 2017 Jul 12.

Chiann, K., Xuan, W. M., Hossain, M. S., Hanapi, N. S. M., Hashima E Nasreen, H. E., Islam,M. Z., Ahmed, I. A., Haque, N. (2021), Awareness and attitude towards dental pulp stem cell banking among Malaysians, Health Policy and Technology, 10 (2); 100502

ClinicalTrials.gov. Revitalization of immature permanent teeth with necrotic pulps using SHED cells. 2017. Available from: https://clinicaltrials.gov/ct2/show/ ANNALS OF MEDICINE 649.

Farea, M., Husein, A., Halim, A. S., Abdullah, N. A., Mokhtar, K.I., Lim, C. K., Berahim, Z. et al. (2014). Synergistic effects of chitosan scaffold and TGFb1 on the proliferation and osteogenic differentiation of dental pulp stem cells derived from human exfoliated deciduous teeth. Archives of Oral Biology,59:1400-1411.

Ghosh, D., Mehta, N., Patil, A., Sengupta, J. (2016) Ethical issues in biomedical use of human embryonic stem cells (hESCs). Journal of Reproductive Health and Medicine. 2:S37- S47

Govindasamy V, Ronald VS, Abdullah AN, Nathan KR, Ab Aziz, ZA, Abdullah M, et al. Differentiation of dental pulp stem cells into islet-like aggregates. Journal of Dental Research. 2011;90(5):646-52

Gronthos, S., Brahim, J., Li, W., Fisher, L. W., Cherman, N., Boyde, A., et al. (2002). Stem cell properties of human dental pulp stem cells. Journal of Dental Research 81:531-535

Huang, C-Y., Liu, C-L., Ting, C-Y., Chiu, Y-T., Cheng, Y-C., Nicholson, M. W., et al. (2019). Human iPSC banking: barriers and opportunities. Journal of Biomedical Science, 26(1):87;PMID: 31660969.

Lee, J-H., Seo, S-J. (2016). Biomedical Application of Dental Tissue- Derived Induced Pluripotent Stem Cells. Stem Cells International. 2016:9762465;PMID: 27597868.

Hashim, S. N. M., Yusof, M. F. H., Zahari, W., Chandra, H., Noordin, K. B. A. A., Kannan,T. P. et al. (2019). Human amniotic membrane as a matrix for endothelial differentiation of VEGF-treated dental stem cells. Cellular and Molecular Bioengineering, 12 (6): 599-613
Miura, M., Gronthos, S., Zhao, M. et al. (2003). SHED: stem cells from human exfoliated deciduous teeth. Proceedings of the National Academy of Sciences of the United States of America. 100:5807-12

Murphy, C. M., O'Brien, F. J., Little, D. G., Schindeler, A. (2013). Cell-scaffold interactions in the bone tissue engineering triad. European Cells \& Materials, Sep 20;26:120-32.

Nakashima, M., Iohara, K., Murakami, M., et al. (2017). Pulp regeneration by transplantation of dental pulp stem cells in pulpitis: a pilot clinical study. Stem Cell Research \& Therapy, 8:61.

Sun, H. H., Chen, B., Zhu, Q. L., Kong, H., Li, Q. H., Gao, L. N., et al. (2014). Investigation of dental pulp stem cells isolated from discarded human teeth extracted due to aggressive periodontitis. Biomaterials 35, 9459-9472.

Xuan, W. M., Chiann, K., Hossain, M. S., Ismail, M. F., Haque, N. (2021). present status of research on the regenerative potential of dental pulp stem cells in malaysia: a systematic review. Progress in Stem Cell. 8(1):304-309

Yang, J. W., Zhang, Y. F., Sun, Z. Y., Song, G. T., and Chen, Z. (2015b). Dental pulp tissue engineering with bFGF-incorporated silk fibroin scaffolds. Journal of Biomaterials Applications. 30, 221-229.

Yang, J. W., Zhang, Y. F., Wan, C. Y., Sun, Z. Y., Nie, S., Jian, S. J., et al. (2015a). Autophagy in SDF-1 $\alpha$-mediated DPSC migration and pulp regeneration. Biomaterials. 44, 11-23. 